\title{
How to Foresee and Capture the Effects of RFID Implementation
}

\author{
Kristin Hergot and Lars Skjelstad \\ SINTEF Technology and Society, Industrial Management, S.P. Andersensv. 5, 7465 \\ Trondheim, Norway \\ lars.skjelstadasintef.no
}

\begin{abstract}
RFID technology is, according to both industry and academia, one of the most promising new technologies for improving logistics and manufacturing excellence this decade. This research provides a structured approach for identifying benefits from RFID-implementation, which would be useful for the many manufacturing companies that are still in the phase of considering employing this technology. Based on action research in two Norwegian pilot implementation projects, a framework has been developed for foreseeing, sorting, and capturing the effects of introducing RFID in goods manufacturing value chains. Effects are described in several general performance objective areas, such as cost, time, quality and environment, rather than being calculated in terms of money solely. The key is to systematically highlight possible affected performance areas and the consequences these effects have on each other and on different parts of the value chain.
\end{abstract}

Keywords: RFID implementation, performance measurement, manufacturing improvement.

\section{Introduction}

The objective of this research has been to develop a framework for identifying the effects of RFID technology implementation, and to test the framework alongside two pilot implementation cases. In some industries, there is already a demand for RFID technology simply to qualify for being a supplier, or to fulfil governmental rules. However, whether or not to employ the technology for others, off course to a high degree depends on the benefits one can foresee before the decision is made. The technology also allows for some re-engineering, and the challenge is to overview what kind of impact RFID can have on your own business.

The paper suggests how to foresee, sort and capture the effects of introducing RFID in goods manufacturing value chains. The key is to systematically highlight possible effects and the consequences these effects have on each other, in several performance dimensions. A structured approach, both during initial stipulation and later during actual identification of real benefits, would be useful for all companies considering employing this technology. Upfront the implementation project, the technology itself is in focus, and few, if any, in the pilot team can foresee all effects that might follow. 
Being aware of possible effects in different performance areas before starting RFID implementation projects will influence the possibilities to set goals and reach them. The framework tends to guide the project members in what effects to look for and which ones to avoid.

Since RFID technology primarily is used to gain more control or automate processes related to the main value creating process, the decision to invest and employ is hard to make in some cases. It is not obvious where effects will occur.

\section{Method}

The main research method used is action research. Collaboration with two Norwegian industrial companies has given insight in different phases of the RFIDimplementation process. The project is funded by the Norwegian Research Council, and the aim has been to implement RFID in pilot areas within the companies in order to learn about the technology and possible effects from it in the value chain, both in the pilot and in a thought future situation where it is rolled out in all processes. In workshops, discussions about possible gain have been initialized at several stages in the development process, from early planning sessions to meetings after the pilot implementation in one of the cases. During the whole process, it has been hard to be conclusive about the effects, but it has been possible to generate discussions about where effects most likely can be expected. This has led to the development of a framework for others to use in similar situations.

Literature reviews have been performed on trade-offs, performance objectives, RFID business cases, decision making under uncertainty and operations management.

This research also includes conceptual development of a new method for a new situation. Results are still under testing and finalizing in the second pilot. The plan is to follow this company throughout implementations and conclusions, to go through all phases of the decision making process.

\section{Cases}

The research involves two case companies that want to test the RFID technology in order to gain experience with the technology itself and of course to reveal possible effects it might have on their business. Both companies are treated confidentially. One of them is within the food industry, and the other is a manufacturer of sports equipment. In this section, a general description and their strategic goals are referred to. Then, in later sections, the cases serve as examples within the topics discussed.

\subsection{Food Manufacturer}

The food company is a dairy that makes cheese at two different sites. In the first plant, cheese is made in large blocks, packed and stored for maturation. The cheese is then brought to the other plant where it is split and packed in consumer packages. Finally it is stored and shipped together with other goods.

The main motivation for this producer to investigate possibilities with the RFID technology is the advantage to document the history and origin of the product 
(traceability). In addition, this producer based its interest in improving price and quality of the products. Also the products have limited lasting ability, and efforts are invested in keeping track of stock. Today's solution is a printed label on every pallet with a bar code on it. In the pilot, RFID tags were introduced as a second label, and put on every pallet in the same operation that puts on the existing label. The existing information system and the RFID test system were used in parallel during the test in order to verify the results. Antennas were mounted on three stocks and both the out gate at the first plant and the in gate at the second.

\subsection{Sports Equipment Manufacturer}

The sports company manufacture personal sports equipment in a large scale. The products are sold to end users from sports-shops. The end users need to try the products in the shop in order to make sure they get the right equipment. The manufacturer has to make many variants and the stores have to keep stock of different products. The equipment is seasonal, but the production goes around the year. This means that for a long period products are made to stock whilst the plans are based on prognosis. The main motive for employing RFID is quality, price and delivery time. Also to keep track of individual products is a resource demanding task today. In this case, the tags are embedded in the products, and three antennas have been set up in the production.

\section{Discussion}

Setting the goal to be identification of all possible effects from employing RFID, determining the right performance dimensions to look for improvements within is crucial. The traditional way of evaluating an investment, at least in production technology, is to look at the payback time, the net present value and other economic values. These indicate to the decision makers whether the investment is good or not, even compared to alternatives. When it comes to investments in RFID systems however, this paper argues that more performance dimensions must be considered than monetary solely, at least in the beginning and the first part of the employment period. This is due to two reasons mainly. First, the technology is not a direct process technology, but rather a support technology and an information handling technology. Also for such technologies, efficiency effects can be redeemed directly, but other and indirect effects can be expected too. Other effects can be found in the environmental-, time-, and quality- dimensions. Long-term aspects should be considered when investing in support technologies such as RFID. Second, what is regarded as a quality- or environmental- effect in the first place (blue, future dollars), can be turned into monetary results (green, current dollars) at a later stage. Customers might find any improvement favourable in time, and hence choose our product in the long run.

When assessing the feasibility of an RFID implementation project, both qualitative approaches, referring to strategy or level of logistics service delivered to customers, and quantitative approaches, assessing costs and savings resulting from the implementation of a to-be scenario or a re-engineered process, can be used [1]. The objectives for an RFID implementation project should be to do something faster or better, and be in coherence with the company's strategic goals and its key performance indicators 
[1]. Effects should be sought in different area of the value chain, such as manufacturing, receiving and dispatch, and retail.

Rush [2] uses a quantitative approach and has developed a RFID value calculator to work out RFID's total cost savings and return on investment, based on inventory costs, customer service costs (fill rates) and labour costs. However, financial measures are lagging and can be too narrow-focused on the bottom line, taking the focus off longer-term beneficial improvements [3].

To get a broader picture, one must use qualitative approaches, with focus on strategically important performance areas, in order to get a balanced view of the company [4] and its value chain and to link the company's long-term strategy with its shortterm actions. Several authors have for different purposes defined their own sets of measures (RFID benefit identification [5], general performance measuring $[6,7,8]$ and designing for manufacture [9]), and a comparison of these can be seen in the table below. The overall performance relies on all these aspects and consequences are expected in them all, whether they are considered or not, and looking at all of them will allow a complete evaluation and prevent problems from being shifted from one area to another [9]. In this research, 9 dimensions are selected based on previous work;

Table 1. Selected performance dimensions to identify RFID-benefits within

\begin{tabular}{|c|c|c|c|c|c|}
\hline & \begin{tabular}{|c|} 
Fabricius \\
{$[9]$}
\end{tabular} & $\begin{array}{c}\begin{array}{c}\text { Slack et al } \\
{[6]}\end{array} \\
\end{array}$ & $\begin{array}{c}\begin{array}{c}\text { Supply-Chain } \\
\text { Council [7] }\end{array} \\
\end{array}$ & \begin{tabular}{|c|}
$\begin{array}{c}\text { Kaplan et al } \\
{[8]}\end{array}$ \\
\end{tabular} & $\begin{array}{c}\text { Rhensius et al } \\
{[5]}\end{array}$ \\
\hline Cost & Production costs & Cost & Cost, Asset & Financial & $\begin{array}{l}\text { Turnover, Depreciation, } \\
\text { Failure cost, Capital } \\
\text { commitment }\end{array}$ \\
\hline Efficiency & Efficiency & & & \multirow{7}{*}{$\begin{array}{l}\text { Internal } \\
\text { business } \\
\text { process, } \\
\text { Customer }\end{array}$} & \multirow[t]{7}{*}{ Process performance } \\
\hline Time & Lead time & Speed & Responsiveness & & \\
\hline Precision & & Dependability & Reliability & & \\
\hline Flexibility & Flexibility & Flexibility & Flexibility & & \\
\hline Quality & Quality & Quality & & & \\
\hline Environment & Environmental effects & & & & \\
\hline Risk & Risk & & & & \\
\hline Developement & & & & $\begin{array}{l}\text { Learning and } \\
\text { growth }\end{array}$ & Personnel \\
\hline
\end{tabular}

Costs may include inventory costs, labour costs, waste or shrinkage costs, and administrative costs. RFID may reduce costs through reducing the need for inventory through better control and reduced safety stock. It also enables information sharing in real-time, and may therefore prevent the bullwhip effect and reduce cycle stocks [10]. RFID may result in reduction of labour and administrative costs due to reduced manual registration. Increased control might also reduce waste and shrinkage costs [11]. In the food case, manual labour can be reduced at goods reception. In the sports case manual labour was found to be reduced in production.

Efficiency is one of the major effects of RFID implementation [12]. Automation of information collection reduces work, and more information can be collected without disturbing other work. Both in the food and sports case automatic inventory counts is expected to be realised.

Focus on time is still important in today's competitive environment. Shortened lead times is a direct improvement. RFID can improve lead times through reduction of manual labour. Delivery lead time is one of the most important performance 
dimensions in the sports manufacturer's case. In the food manufacturer's case, shorter lead times will increase the shelf times of perishable goods.

Precision is a major competitive determinant [13] and an important factor in logistics performance. It is often more important to be able to deliver to the customer at the promised time (not to late or to early) than to be able to deliver fast. RFID can help increase precision, transparency and visibility of information through timely and accurate data. In the food case, improved recalls is important both to health risk and cost. In the sports case, more precise information about inventories will improve planning and shipping.

RFID can help increase flexibility through providing real-time information. Real time information helps improve balancing of processes and hence the manufacturer's flexibility in handling new or changed jobs [12].

Lowest possible level of quality control, rework and scrap, is important [9]. RFID can help visualise potential problems at an early stage [12]. RFID may also ease documentation of quality of the products (temperature sensitive products). Quality is of strategically importance and one of the most central performance dimensions in the sports manufacturer's case. With RFID, dynamic expiration dates can be enabled.

Environmental friendliness can be a competitive advantage [14] as well as an ethical factor. RFID can be employed to reduce waste from perishable products due to more precise recalls. Tags might help end-of-life operations.

Risk can be reduced through accurate tracking of the goods. More accurate and fast recalls reduces the risk for possible bad reputation. The risk of obsoleteness and stock-outs can be reduced through increased control of product whereabouts [15].

Development work is part of the daily business. Automatic documentation of operations and material flows throughout the value chain forms the best basis for further improvements on all the above mentioned dimensions.

As can be seen in the above discussion, direct effects on one dimension can also have indirect effects on other dimensions.

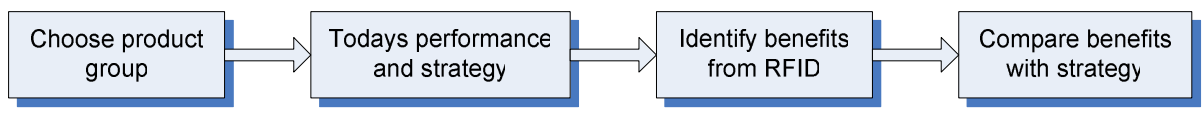

Fig. 1. Process to secure that improvements gained are in line with company strategy

A framework to identify improvements must consider if they are aligned with the company strategy.

This can be shown in figure 1, where step 3 is the use of the framework, and step 2 and 4 compare with the strategy.

1) Choose product group for your pilot implementation.

RFID technology can be used in many areas, and perhaps be rolled out in the entire organisation over time. However, during the introducing project it is recommended to focus on one single product group.

2) What is your strategy in this market segment, and how well are you performing?

This step will give you an idea of what you need to improve. The gap between your goals and your performance should be known. 


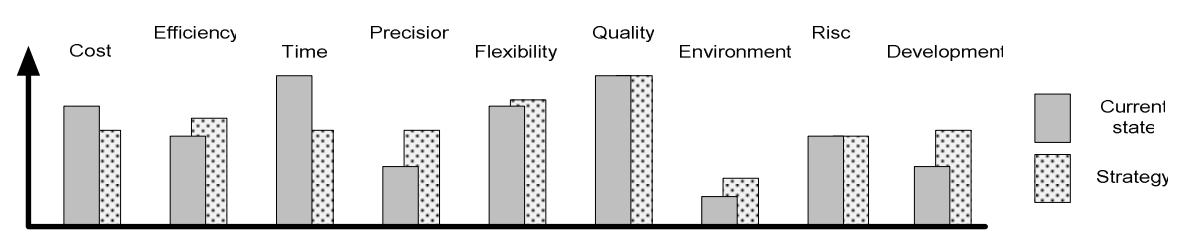

Fig. 2. Current performance compared to strategic goals (example)

3) Use the framework to consider possible benefits from employing RFID.

By using the framework, possible gains from RFID will be highlighted.

4) Compare to your strategy, and see if investment in RFID is the right action.

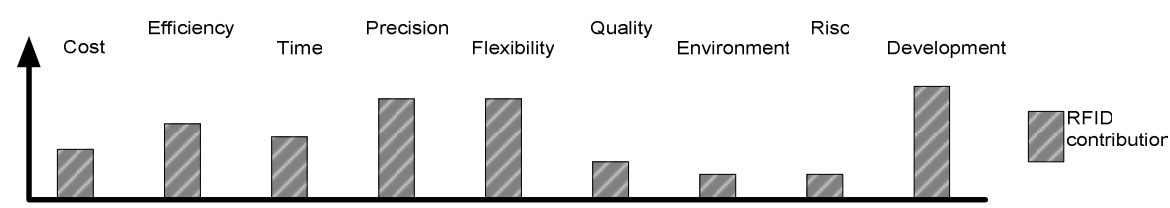

Fig. 3. Contribution from employing RFID (example)

\section{Results}

A framework to foresee and capture improvements likely to be achieved from employing RFID is suggested using many performance dimensions. In the table below, a single sample is given for the dimension of quality. The information in the table is from the food company.

Table 2. Framework example showing the quality dimension from the food case

\begin{tabular}{|l|l|l|l|}
\hline Advantage / disadvantage & $\begin{array}{l}\text { Direct effect or } \\
\text { consequence }\end{array}$ & $\begin{array}{l}\text { Pos. } \\
\text { eff. }\end{array}$ & $\begin{array}{l}\text { Neg. } \\
\text { eff. }\end{array}$ \\
\hline The registrations will give statistics for improvement projects & $\mathrm{D}$ & $\mathrm{x}$ & \\
\hline Possibility to document quality (temperature) and times in the value chain & $\mathrm{D}$ & $\mathrm{x}$ & \\
\hline Receipt of goods at the second plant. Quality assurance and time saving & $\mathrm{D}$ & $\mathrm{x}$ & \\
\hline Crew in reception plant 2 can be reduced with 0,5 - 1 man-labour year & $\mathrm{C}(\mathrm{cost})$ & $\mathrm{x}$ & $\mathrm{x}$ \\
\hline Temperature is an important theme for further development of solutions & $\mathrm{D}$ & $\mathrm{x}$ & \\
\hline
\end{tabular}

In addition to the advantages listed, it should be denoted if it is a direct advantage or a consequence from an advantage listed in one of the other dimensions. In the example, reduced staff is registered as a consequence from an advantage listed as a direct effect in the cost dimension. It can also be seen that in the quality dimension, reduced staff could actually be a disadvantage. Loosing the operator in the receiving area can represent a risk and a threat with respect to quality. Of course the framework consists of one table per performance dimension. 
To produce the list of possible advantages or disadvantages, one has to go through three steps;

a) Brainstorming session with every involved person in the project. This will cover benefits that people think about first, and what might follow from other persons input. The list must than be sorted according to the performance dimensions.

b) For each performance dimension, discuss general and known effects. This sets the mind to think of one focused theme at a time.

c) Check if the identified effects have consequences on one or several of the other performance dimensions. For example cost savings on personnel might represent a risk or a negative effect when it comes to quality.

The team must consist of persons from all parts of the value chain. Effects that occur in one part of the value chain are considered with respect to consequences in another part and in other dimensions. One then need to look in detail at the positive and negative effects at the operational level to get a true and balanced picture. With the final list of possible effects, created and shared by the whole implementation team, it will be easier to reap the foreseen effects and reach company goals.

\section{Conclusion}

Participation in two pilot RFID implementation projects has gained insight about possible effects this new emerging technology might have on a manufacturing business. Project focus shift from pure technology interest in the beginning, to performance focus towards the end. It seems as if the participants need to overcome the basics of the RFID technology as such, before knowledge about how to exploit the technology in future business models are considered.

Findings show that implementing RFID technology influences on several performance criteria. Opportunities for process reengineering create additional positive effects, and a certain amount of such reengineering is in fact necessary to get maximum results. To separate effects from the introduction of new technology and the reengineering effort can be challenging, but also in some cases uninteresting.

The framework is developed and used in pilots with a food company and a sports equipment company. Future research should be conducted on complete implementations and include other industries to gain valuable feedback. As more companies follow up their implementations in a similar manner, generic knowledge about what to anticipate from exploiting this technology will be improved. There is still work to be done on how to estimate the effects once they are identified. This is suggested done with trade-off techniques.

\section{References}

1. Bottani, E., Hardgrave, B., Volpi, A.: A methodological approach to the developement of RFID supply chain projects. International Journal of RF Technologies: Research Applications 1(2), 131-150 (2008) 
2. Rush, T.: How to Calculate RFID's Real ROI. Presentation at RFID Journal Live. Orlando USA (2009)

3. Henricson, P., Ericsson, S.: Measuring construction industry competitiveness: A holistic approach. Paper Presented at the Research Week International Conference. The Queensland University of Technology, Brisbane (2005)

4. Tangen, S.: An overview of frequently used performance measures. Work Study 52(7), 347-354 (2003)

5. Rhensius, T., Dünnebacke, D.: RFID Business Case Calculation. RFID Systech, Bremen (2009)

6. Slack, N., Chambers, S., Johnston, R.: Operations Management, 4th edn. Pearson Education, London (2004)

7. Supply-Chain Council: Supply chain Operations Reference Model SCOR Version 8.0 (2006), http: / /www. supply-chain.org/resources / scor

8. Kaplan, R.S., Norton, D.P.: Using the Balanced Scorecard as a Strategic Management System. Harvard Business Review (January-February 1996)

9. Fabricius, F.: Design for manufacture DFM Guide for improving the manufacturability of industrial products. Eureka, Lyngby (1994)

10. Netland, T.H., Dreyer, H., Strandhagen, J.O.: Demand driven control concepts - foresight in the effects of RFID. In: 15th International Annual EurOMA Conference, Groningen, The Netherlands (2008)

11. Tajima, M.: Strategic value of RFID in supply chain management. Journal of Purchasing \& Supply Management 13, 261-273 (2007)

12. Shibata, T., Tsuda, T., Araki, S., Fukuda, K.: RFID-based production process monitoring solutions. NEC Tech. J. 1(2), 77-81 (2006)

13. Alfnes, E., Strandhagen, J.O.: Enterprise design for mass customisation: The control model methodology. International Journal of Logistics: Research and Applications 3(2) (2000)

14. Andersen, B., Fagerhaug, T.: "Green" performance measurement. International Journal of Business Performance Management 1(2) (1999)

15. Fleisch, E., Tellkamp, C.: Inventory inaccuracy and supply chain performance: a simulation study of a retail supply chain. International Journal of Production Economics 95(3), 373-385 (2004) 